\title{
Molecular diversity of serial Cryptococcus neoformans isolates from AIDS patients in the city of São Paulo, Brazil
}

\author{
Marilena A Martins, Mara CSM Pappalardo*, Márcia SC Melhem, \\ Vera L Pereira-Chioccola/ ${ }^{+}$
}

\begin{abstract}
Laboratório de Biologia Molecular de Parasitas e Fungos de Interesse em Saúde Pública, Serviço de Parasitologia, Instituto Adolfo Lutz, Av Dr Arnaldo 351, 01246-902 São Paulo, SP, Brasil * Departamento de Doenças Infecciosas, Instituto de Infectologia Emílio Ribas, São Paulo, SP, Brasil
\end{abstract}

\begin{abstract}
Despite highly active anti-retroviral therapy, cryptococcal meningoencephalitis is the second most prevalent neurological disease in Brazilian AIDS patients, being frequently a defining condition with several episodes. As knowledge of Cryptococcus neoformans isolates in the same episode is critical for understanding why some patients develop several episodes, we investigated the genotype characteristics of $\mathrm{C}$. neoformans isolates in two different situations. By pulsed field gel electrophoresis and random amplifield polymorphic DNA analysis, 54 isolates from 12 patients with AIDS and cryptococcosis were analyzed. Group 1 comprised 39 isolates from nine patients with a single episode and hospitalization. Group 2 comprised 15 isolates from three patients with two episodes and hospitalizations. Except for three patients from group 1 probably infected with a single C. neoformans isolate, the other nine patients probably were infected with multiple isolates selected in different collection periods, or the infecting isolate might have underwent mutation to adapt and survive the host immune system and/or the antifungal therapy. However, the three patients from group 2 presented genetic diversity among isolates collected in both hospitalizations, possibly having hosted the initial isolate in both periods. These data, emphasize that Cryptococcus diversity in infection can contribute to strategies of treatment and prevention of cryptococcosis.
\end{abstract}

Key words: cryptococcal meningoencephalitis and AIDS - molecular analysis of Cryptococcus neoformans isolates

Cryptococcus neoformans is an encapsulated yeast and opportunistic human pathogen that causes cryptococcosis. The disease is the most common cause of systemic mycosis in immunodeficient patients. The infection begins when the yeast penetrates the organism, lodging primarily in the lungs, and later presenting a notable tropism for the central nervous system (KwonChung \& Bennett 1992, Perfect \& Casadevall 2002). The course of infection is a serious and often life-threatening disease, principally in AIDS patients. Meningoencephalitis is typically observed in later stages of human immunodeficiency virus infected patients (Calvo et al. 1990, Mitchell \& Perfect 1995, Pappalardo \& Melhem 2003).

The introduction of the highly active antiretroviral therapy (HAART) has decreased the incidence of cryptococcosis in AIDS patients in areas where it is available. The high cost of HAART and the complicated logistical infrastructure necessary for its administration have precluded its use in less-developed countries. Currently, the prevalence of AIDS-related brain disorders continues to explain a considerable proportion of the mortality and morbidity (Sacktor 2002). In Brazil, despite the HAART treatment, cryptococcosis is the second most prevalent

${ }^{+}$Corresponding author: pchioccola@ial.sp.gov.br Received 25 January 2007

Accepted 25 October 2007 neurological disease in AIDS patients and an AIDSdefining condition. Usually, the patients seek a hospital after the appearance of meningoencephalitis signs (Oliveira et al. 2006). Therefore, cryptococcosis, AIDS and low CD4 cells index are frequently diagnosed simultaneously (Santos et al. 2002, Pappalardo \& Melhem 2003, Silva \& Araújo 2005).

The complexity of $C$. neoformans infection in immunosupressed patients led to the development of diverse studies during the last decade. Significant progress has been made by morphological, physiological, ultrastructural, and molecular approaches. Two varieties have been widely accepted: $C$. neoformans var. neoformans (serotypes A, D, and AD) and C. neoformans var. gattii (serotypes B and C) (Ikeda et al. 1985, KwonChung 1998). Later, C. neoformans var. neoformans serotype A was proposed as new variety named $C$. neoformans var. grubii (Franzot et al. 1999). At present, the etiologic agent of cryptococcosis is classified into two species, $C$. neoformans (serotypes A and D) and $C$. gattii (serotypes B and C) (Kwon-Chung \& Varma 2006). In parallel, epidemiological studies have shown high prevalence of $C$. neoformans serotype A in patients with AIDS (Calvo et al. 1990, Mitchell \& Perfect 1995, Nishikawa et al. 2003, Pappalardo \& Melhem 2003).

The molecular methods contributed for identifying genetic differences among $C$. neoformans varieties (Currie et al. 1994, Barchiesi et al. 1995, Chen et al. 1996, Klepser \& Pfaller 1998, Meyer et al. 1999, Calvo et al. 2001, García-Bermejo et al. 2001, Litvintseva et al. 2006, Almeida et al. 2007). Some studies suggested that the majority of cases are due to persistence of the 
original infecting strain, while others suggested that the infections may result from acquisition of new strains. Mixed infections are also possible since environmental sites may contain more than one strain (Currie et al. 1994, Barchiesi et al. 1995, Haynes et al. 1995, Chen et al. 1996, Sullivan et al. 1996, Sukroongreung et al. 2001, Barreto de Oliveira et al. 2004, Igreja et al. 2004, Jain et al. 2005). These controversial studies led us to suppose that all situations could occur in patients with different episodes. However, the knowledge of the C. neoformans strains in the same episode is particularly important to understand why some patients could develop multiple episodes.

This study aimed to understand two situations in cryptococcal meningoencephalitis. First, the genotype characteristics of different $C$. neoformans samples isolated from the same patient, in a single infection and hospitalization. Next, the genotype characteristics of different C. neoformans samples isolated from the same patient, but with two infection episodes and hospitalizations. We used pulsed field gel electrophoresis (PFGE) for chromosomal analysis, and small modifications in DNA were analyzed by random amplified polymorphic DNA analysis (RAPD-PCR), with two random sequences as primer. The genotypic profiles observed in isolates collected from patients living in the city of São Paulo can partially explain the epidemiological and clinical implications in this meningoencephalitis highly lethal to humans.

\section{PATIENTS, MATERIALS AND METHODS}

Patients and samples - Samples of 54 C. neoformans were isolated from cerebrospinal fluid (CSF) from 12 patients with AIDS and cryptococcal meningoencephalitis, living in the city of São Paulo, Brazil. AIDS diagnosis was determined by criteria defined in the Center for Disease Control and Prevention criteria (CDC 1999). All patients presented less than $100 \mathrm{CD} 4$ lymphocytes $/ \mathrm{ml}$ of blood when admitted for treatment for both infections at the Instituto de Infectologia Emilio Ribas, São Paulo, SP, Brazil.
Patients were divided in two groups according the number of hospitalizations. Group 1 was composed of nine patients (39 C. neoformans isolates) with one cryptococcal meningoencephalitis episode and a single hospitalization in the acute phase. The first CSF collection (collection a- 0 , Table I) was performed before the specific treatment for cryptococcal meningoencephalitis. The treatment was made according to Saag et al. (1992) and CDC (1999), and consisted of intravenous amphotericin B 40-50 mg/day for 2-8 weeks, followed by fluconazole $200 \mathrm{mg}$ /day until the patient was clinically stable. Patients who developed toxic reactions to amphotericin B were treated with oral fluconazole 800 $\mathrm{mg}$ /day for 10-12 weeks. Group 2 was composed of three patients (15 C. neoformans isolates) with at least two cryptococcal meningoencephalitis episodes and two hospitalization periods. Their first CSF collection and antifungal therapy were made as for patients from group 1. In the second clinical episode they were hospitalized and treated again. Tables I and II show details on the isolates recovered from each patient. The Ethics Committee of both institutions approved this study (protocols IIER 055/05 and IALBM 023/05).

Laboratorial diagnosis - The CSF samples were collected in aseptic conditions, immediately added to sterile tubes, sent to laboratory and immediately processed. Each sample was centrifuged at 3,000 $\mathrm{g}$ for 10 $\min$. One drop of the pellet was used for the India ink preparation. The remaining pellet was spread on a tube contained Sabouraud dextrose agar, and incubated at $30^{\circ} \mathrm{C}$ during 15 days (Kwon-Chung \& Bennett 1992). After growing, the isolates were identified using the Vitek YBC card (BioMérieux). The isolates were streaked on Niger seed agar plates. After incubation at $30^{\circ} \mathrm{C}$ for seven days no macroscopic difference was observed in the colonies. For biochemical characterization, a single wellseparated yeast colony was selected at random and sub cultured in tube with Sabouraud dextrose agar at $30^{\circ} \mathrm{C}$ for 24-48 h. All clinical isolates were identified as $C$.

TABLE I

Characteristics of clinical Cryptococcus neoformans isolates from cerebrospinal fluids of patients with one episode and one hospitalization (group 1)

\begin{tabular}{|c|c|c|c|c|c|c|c|c|c|c|c|}
\hline \multirow{4}{*}{$\frac{\text { Patient code }}{\mathrm{C} 1}$} & \multirow{3}{*}{\multicolumn{8}{|c|}{ Sample code - day of collection ${ }^{a}$}} & \multicolumn{3}{|c|}{ N. of detected genotypes (similarity) ${ }^{b}$} \\
\hline & & & & & & & & & \multirow[b]{2}{*}{ PFGE } & \multicolumn{2}{|c|}{ RAPD-PCR } \\
\hline & & & & & & & & & & $\operatorname{Pr} 3^{c}$ & $\operatorname{Pr} 4^{c}$ \\
\hline & $\mathrm{a}-0$ & $b-16$ & & & & & & & $1^{d}$ & $1^{d}$ & $1^{d}$ \\
\hline $\mathrm{C} 2$ & $\mathrm{a}-0$ & $b-26$ & $c-27$ & d-29 & & & & & $1^{d}$ & $1^{d}$ & $2(0.71)$ \\
\hline $\mathrm{C} 3$ & $\mathrm{a}-0$ & b-6 & $\mathrm{c}-7$ & $\mathrm{~d}-8$ & & & & & $1^{d}$ & $1^{d}$ & $2(0.75)$ \\
\hline $\mathrm{C} 4$ & $\mathrm{a}-0$ & $b-3$ & $\mathrm{c}-4$ & $\mathrm{~d}-8$ & e-9 & $f-10$ & g-11 & & $1^{d}$ & $1^{d}$ & $1^{d}$ \\
\hline $\mathrm{C} 5$ & $\mathrm{a}-0$ & b-20 & & & & & & & $2(0.60)$ & $2(0.50)$ & $2(0.39)$ \\
\hline C6 & $\mathrm{a}-0$ & $b-5$ & $\mathrm{c}-7$ & $\mathrm{~d}-10$ & e-12 & $f-25$ & $\mathrm{~g}-27$ & h-29 & $2(0.60)$ & $1^{d}$ & $1^{d}$ \\
\hline C7 & $\mathrm{a}-0$ & b-16 & $c-24$ & d-31 & & & & & $1^{d}$ & $1^{d}$ & $1^{d}$ \\
\hline $\mathrm{C} 8$ & $a-0$ & b-2 & $c-9$ & $\mathrm{~d}-23$ & & & & & $2(0.50)$ & $2(0.51)$ & $2(0.45)$ \\
\hline C9 & $a-0$ & b-16 & $c-21$ & $\mathrm{~d}-30$ & & & & & $1^{d}$ & $2(0.67)$ & $2(0.57)$ \\
\hline
\end{tabular}

$\bar{a}$ : sample code (letter) and number of days after the first (a-0) cerebrospinal fluid collection; $b$ : similarity coefficient $\left(S_{A B}\right)$ between patterns (pair of isolates); $c$ : primers' code; $d$ : identical isolates, with $S_{\mathrm{AB}}$ between 0.98-1.00. 
TABLE II

Characteristics of clinical Cryptococcus neoformans isolates from cerebrospinal fluids of patients with two episodes and hospitalizations (group 2)

\begin{tabular}{|c|c|c|c|c|c|c|c|}
\hline \multirow[b]{3}{*}{ Patient code } & \multirow[b]{3}{*}{ Hospitalization } & \multirow{3}{*}{\multicolumn{3}{|c|}{ Sample code-day of collection ${ }^{a}$}} & \multicolumn{3}{|c|}{ N. of detected genotypes (similarity) $b$} \\
\hline & & & & & \multirow[b]{2}{*}{ PFGE } & \multicolumn{2}{|c|}{ RAPD-PCR } \\
\hline & & & & & & $\operatorname{Pr} 3^{c}$ & $\operatorname{Pr} 4^{c}$ \\
\hline \multirow[t]{2}{*}{$\mathrm{C} 10$} & $1 \mathrm{st}$ & & b-10 & $\mathrm{c}-20$ & $1^{d}(0.67)$ & $1^{d, e}(0.40,0.50)$ & $1^{d}(0.57)$ \\
\hline & 2 nd & $d-155$ & e-160 & $\mathrm{f}-163$ & $1^{d}$ & $3^{e}$ & \\
\hline \multirow[t]{2}{*}{$\mathrm{C} 11$} & $1 \mathrm{st}$ & $\mathrm{a}-0$ & & & $1^{e}(0.40)$ & $1(0.52,0.69)$ & $1(0.41)$ \\
\hline & 2nd & b-75 & $\mathrm{c}-84$ & d-86 & $2^{e}$ & 2 & \\
\hline \multirow[t]{2}{*}{$\mathrm{C} 12$} & $1 \mathrm{st}$ & $\mathrm{a}-0$ & $\mathrm{~b}-5$ & c-10 & $3(0.58)$ & $1^{d}(0.67)$ & $1^{d}(0.52)$ \\
\hline & 2nd & e-34 & & & 1 & 1 & \\
\hline
\end{tabular}

$a$ : sample code (letter) and number of days after the first (a-0) cerebrospinal fluid collection; $b$ : similarity coefficient $\left(S_{\mathrm{AB}}\right)$ between patterns (pair of isolates); $c$ : primers' code; $d$ : identical isolates, with $S_{\mathrm{AB}}$ between 0.98-1.00; $e$ : identical patterns in both hospitalizations.

neoformans by a positive urease test; a negative nitrate test (assimilation testing performed in Wickerham's yeast nitrogen base); an ability to grow at $37^{\circ} \mathrm{C}$; brown colony color in Niger seed agar; no color change in canavanine-glycine-bromothymol blue agar; and negative Dproline assimilation (Dufait et al. 1987, Kwon-Chung \& Bennett 1992, Kwon-Chung 1998). C. neoformans clinical isolates were maintained in brain heart infusion medium containing $20 \%$ glycerol and frozen at $-20^{\circ} \mathrm{C}$ until genotyping.

Yeast preparation for genotyping - To obtain good PFGE profiles in order to discriminate $C$. neoformans samples, several procedures were established. Yeast wall digestion was made with a high-quality enzyme in ideal biochemical conditions, such as $\mathrm{pH}$ and temperature, to prevent chromosomal DNA degradation by cryptoccocal nucleases. Electrophoretic run and its correlation with electrical tension were well established with the purpose of obtaining a good band separation. Each band was correlated with a chromosome; abundant stained bands may correspond two or more chromosomes (Wickes et al. 1994). The protocols used for chromosomal DNA preparation and PFGE were those previously described (Perfect et al. 1989, Barchiesi et al. 1995), with some modifications. Frozen isolates were thawed and grown on Niger seed agar plates with $0.05 \%$ chloramphenicol at $30^{\circ} \mathrm{C}$. After $48 \mathrm{~h}$, a single well-separated yeast colony was selected at random and transferred in to $20 \mathrm{ml}$ of YEPD (1\% yeast extract, 2\% dextrose, 2\% Bacto Peptone). The yeasts were grown at $30^{\circ} \mathrm{C}$ for $20 \mathrm{~h}$ in a shaking incubator at $90 \mathrm{~g}$. The cells were harvested by centrifugation and washed three times in sterile distilled water. The protoplasts were obtained by digestion of yeast capsules and walls by the incubation at $37^{\circ} \mathrm{C}$ for $2-$ $3 \mathrm{~h}$ with $10 \mathrm{mg} / \mathrm{ml}$ lysing enzyme from Trichoderma harzianum (Sigma Chemical, USA) in CES buffer (20 $\mathrm{mM}$ sodium citrate $\mathrm{pH}$ 5.6, 50 mM EDTA pH 8.0, 0.9 M sorbitol). After incubation, the protoplasts were centrifuged and washed three times in the same buffer at $1,000 \mathrm{~g}$ for $10 \mathrm{~min}$. Each protoplast sample was divided into two aliquots. One was used for PFGE and another for RAPDPCR analysis after DNA extraction.
PFGE - The isolates were performed by electrophoretic karyotype analysis using a contour-clamped homogeneous eletrophoretic field system (CHEF-DRII, Bio-Rad, USA). The protoplasts dissolved in CES buffer were mixed with $1.2 \%$ low-melting-point agarose $(\mathrm{w} / \mathrm{v})$. The mixtures were dispensed into molds to form agarose plugs. After polymerization at $4^{\circ} \mathrm{C}$ for $20 \mathrm{~min}$, the plugs were incubated at $50^{\circ} \mathrm{C}$ for $18 \mathrm{~h}$ with $1 \mathrm{mg} / \mathrm{ml}$ of proteinase $\mathrm{K}$ in $0.01 \mathrm{M}$ Tris $\mathrm{HCl} \mathrm{pH} 7.5,0.45 \mathrm{M}$ EDTA $\mathrm{pH} 8.0,0.01 \% \mathrm{~N}$-laurilsarcozyl. The plugs were washed five times, and stored at $4^{\circ} \mathrm{C}$ in $50 \mathrm{mM}$ EDTA until use. Electrophoreses were performed in 1\% agarose, after plugs insertion, in TBE buffer $(0.044 \mathrm{M}$ Tris-borate, $0.001 \mathrm{M}$ EDTA $\mathrm{pH} 8.0$ ) at $14^{\circ} \mathrm{C}$ and $4.5 \mathrm{~V} / \mathrm{cm}$ in a $\mathrm{CHEF}$ DRII (Bio-Rad). Gels were stained with ethidium bromide after running for $29 \mathrm{~h}$ with switch time ramping from 80 to $200 \mathrm{~s}$. The fragment sizes were based on comparison to a Saccharomyces cerevisiae chromosome DNA molecular weight marker (Bio-Rad) that was included in each gel. The samples were analyzed in duplicate and, at least, two different runs.

DNA purification - The protoplasts were dissolved in a lysis buffer containing $10 \mathrm{mM}$ Tris- $\mathrm{HCl} \mathrm{pH} \mathrm{8.0,} 10 \mathrm{mM}$ EDTA pH 8.0, 0.5\% SDS, 0.01\% N-laurilsarcozyl and $100 \mu \mathrm{g} / \mathrm{ml}$ proteinase $\mathrm{K}$. The mixtures were briefly vortex mixed and incubated at $56^{\circ} \mathrm{C}$ until the complete lyses of the cells (around $120 \mathrm{~min}$ ). DNA was extracted by phenol/ chloroform/ isoamylalcohol method and precipitated by isopropanol (Sambrook et al. 1989). After washing with $70 \%$ ethanol for $10 \mathrm{~min}$ at $10,000 \mathrm{~g}$, the DNA pellet was dissolved in ultra pure water containing RNAase $20 \mu \mathrm{g} / \mathrm{ml}$. DNA concentrations were determined in O.D. at $260 \mathrm{~nm}$, while DNA purity was determined by the ratio of O.D. at 260 and $280 \mathrm{~nm}$. For PCR amplification, $1 \mu \mathrm{l}$ of each sample DNA (85- $90 \mathrm{ng}$ ) was used as DNA template (Sambrook et al. 1989).

$R A P D-P C R$ - The amplifications were carried out with the kit Ready-to-Go/RAPD Analysis Beads (AmershamPharmacia-Biotech). RAPD-PCR beads were composed of 1.5 units Taq DNA polymerase, $10 \mathrm{mM}$ Tris- $\mathrm{HCl} \mathrm{pH}$ 8.3, $30 \mathrm{mM} \mathrm{KCl}, 3 \mathrm{mM} \mathrm{MgCl} 2,400 \mathrm{mM}$ of each dNTP, 
and stabilizers as bovine serum albumin Each reaction was performed adding each DNA template and $25 \mathrm{pmol}$ of the primer in a final volume of $25 \mathrm{ml}$. The selection of primers was determined after testing six primer sequences for exclusive use in RAPD-PCR (AmershamPharmacia-Biotech). Two primers generated the best band profile, and were selected for genotyping the clinical samples: Pr3 (5'GTAGACCCGT3') and Pr4 (5'AAGAGCCCGT3'). The amplifications were performed in an automated thermal cycler (Progene), and consisted of one initial denaturation cycle for $5 \mathrm{~min}$ at $95^{\circ} \mathrm{C}, 45$ cycles of denaturation at $95^{\circ} \mathrm{C}$ for $1 \mathrm{~min}$, annealing at $32^{\circ} \mathrm{C}$ for $1 \mathrm{~min}$, and extension at $72^{\circ} \mathrm{C}$ for $2 \mathrm{~min}$. The procedure was completed by a final cycle extension for $10 \mathrm{~min}$. DNA samples were tested in duplicate, at least twice. Each amplification run contained a negative control (ultra pure water). After thermal cycles, PCR products were electrophoresed in $3.5 \%$ polyacrylamide gels in TBE buffer and stained with ethidium bromide. The sizes of fragments were based on comparison with a 100-bp ladder.

Data analysis - The karyotypes and RAPD-PCR products were visualized under UV light and images were analyzed by the computer program GeneSnap Imager, version 6.08.04. (SynGene). The PFGE and RAPD-PCR patterns of all isolates were compared by visual inspection according to the literature (Barchiesi et al. 1995, Franzot et al. 1997). The bands were compared with those of the molecular weight standards. Isolates with all exactly matched bands were considered to be identical and as the same genotype or pattern. Isolates differing by one or more bands were considered to be different, and identified as having distinct genotypes (two or more patterns). Variations in intensity of RAPD-PCR bands were observed, in spite of standardization of DNA concentrations. In this case, the number and reproducibility of the bands were considered independent of the intensity of band (Chen et al. 1996).

The genetic relationship of the isolates was further determined by the similarity coefficient $\left(S_{\mathrm{AB}}\right)$ in the computer program GeneTools version 3.08.1 (SynGene). The $S_{\mathrm{AB}}$ between patterns for every pair of isolates (A and B) was computed with the formula $S_{\mathrm{AB}}=2 E_{E} /\left(2_{E}+a+b\right)$, where $E$ is the number of common bands in the patterns of $\mathrm{A}$ and $\mathrm{B}, a$ is the number of bands in pattern $\mathrm{A}$ with no correlates in pattern $\mathrm{B}$, and $b$ is the number of bands in pattern B with no correlates in pattern A. $S_{\mathrm{AB}}$ value of $0.90-1.00$ indicates that the banding patterns for isolate A are identical with that of isolate B. $S_{\mathrm{AB}}$ values of 0.80 0.89 represent highly similar, but nonidentical isolates, and may suggest the occurrence of mutation in a single isolate. $S_{\mathrm{AB}}$ values below 0.80 represent unrelated isolates (Soll 2000, Pfaller et al. 2005).

\section{RESULTS}

PFGE and RAPD-PCR allowed to verified genetic differences among samples from 12 patients, showing a good discriminatory capacity and reproducibility. The identical isolates of the same patient exhibited $98-100 \%$ similarity $\left(S_{\mathrm{AB}} 0.98-1.00\right)$. Details on isolates with different patterns of each patient are described below.
The band profile in PFGE and RAPD-PCR (with both primers) of isolates from patients with a single hospitalization (group 1, C1 to C9) as well as from those with two episodes and hospitalizations (group 2, C10 to C12) are in Fig. 1. A summary of patterns (band profiles) and the similarity coefficient for each patients from groups 1 and 2 are in Tables I and II, respectively.

In group 1, all isolates of each patient $(\mathrm{C} 1, \mathrm{C} 2, \mathrm{C} 3$, $\mathrm{C} 4, \mathrm{C} 7$, and $\mathrm{C} 9$ ) presented a single PFGE profile. Isolates of C5, C6, and C8 had two PFGE profiles with low degree of similarity $(0.60,0.60$, and 0.50 , respectively) (Fig.1A). In group 2, three isolates of $\mathrm{C} 10$ obtained in the 1st hospitalization were identical in PFGE. The same was observed in three samples of the 2nd hospitalization. However, the PFGE profile among both hospitalizations was different $\left(S_{\mathrm{AB}}=0.67\right)$. The single isolate, recovered in the 1st hospitalization and one of the 2nd hospitalization of $\mathrm{C} 11$ produced the same PFGE profile. The other two isolates of the 2 nd hospitalization were identical but different from the initial isolate $\left(S_{\mathrm{AB}}\right.$ $=0.40$ ). The four isolates of $\mathrm{C} 12$ showed three PFGE profiles in 1st hospitalization with low degree of similarity $(0.68)$. The single isolates of the 2 nd hospitalization differed from the 1st hospitalization isolates $\left(S_{\mathrm{AB}}=0.58\right)$.

Fig. 1B shows the RAPD-PCR employing Pr3 primer results. All isolates of each patient code as $\mathrm{C} 1, \mathrm{C} 2, \mathrm{C} 3$, $\mathrm{C} 4, \mathrm{C} 6$, and $\mathrm{C} 7$ presented a single RAPD-PCR profile while $\mathrm{C} 5, \mathrm{C} 8$, and $\mathrm{C} 9$ isolates had two band profiles with low degree of similarity $(0.50,0.51$, and 0.67 , respectively). In group 2, C10 presented three different band profiles, one of which was similar in all isolates of the 1 st hospitalization, and one of 2 nd hospitalization. The other two isolates of the 2nd hospitalization presented two different band profiles ( 3 isolates and 3 distinct band profiles with $S_{\mathrm{AB}}$ between $0.40-0.50$ ). Three band profiles were shown in samples of C11. The first indicated the single isolate from the 1st hospitalization, and the second and third ones were from the 2 nd hospitalization (Fig. 1B). The $S_{\mathrm{AB}}$ of the three isolates was between 0.52-0.69. Two different band profiles were shown in isolates of C12. One band profile was shown in four isolates of the 1st hospitalization. The second band profile was shown in a single isolate recovered in the 2 nd hospitalization $\left(S_{\mathrm{AB}}=0.67\right)$.

The Fig. 1C shows RAPD-PCR with $\mathrm{Pr} 4$ results. $\mathrm{Pa}$ tients belonging to group 1 coded as $\mathrm{C} 1, \mathrm{C} 4, \mathrm{C} 6$, and $\mathrm{C} 7$ had a single pattern in all isolates. The isolates $\mathrm{C} 2, \mathrm{C} 3$, $\mathrm{C} 5, \mathrm{C} 8$, and $\mathrm{C} 9$ had two different band profiles with low degree of similarity $\left(S_{\mathrm{AB}}\right.$ of $0.71,0.75,0.39,0.45,0.57$, respectively). In group 2 , the $\operatorname{Pr} 4$ primer produced two different band profiles (one of the 1st hospitalization and one of 2nd hospitalization) for the three patients, the $S_{\mathrm{AB}}$ were $0.57,0.41$, and 0.52 , respectively.

The isolates $\mathrm{C} 1, \mathrm{C} 4$, and $\mathrm{C} 7$ had single band profile in PFGE and RAPD (Table I).

\section{DISCUSSION}

In recent years several studies based on molecular methods have shown that $C$. neoformans isolates exhibit different degrees of genetic heterogeneity among clinical and environmental isolates (Currie et al. 1994, Franzot et 

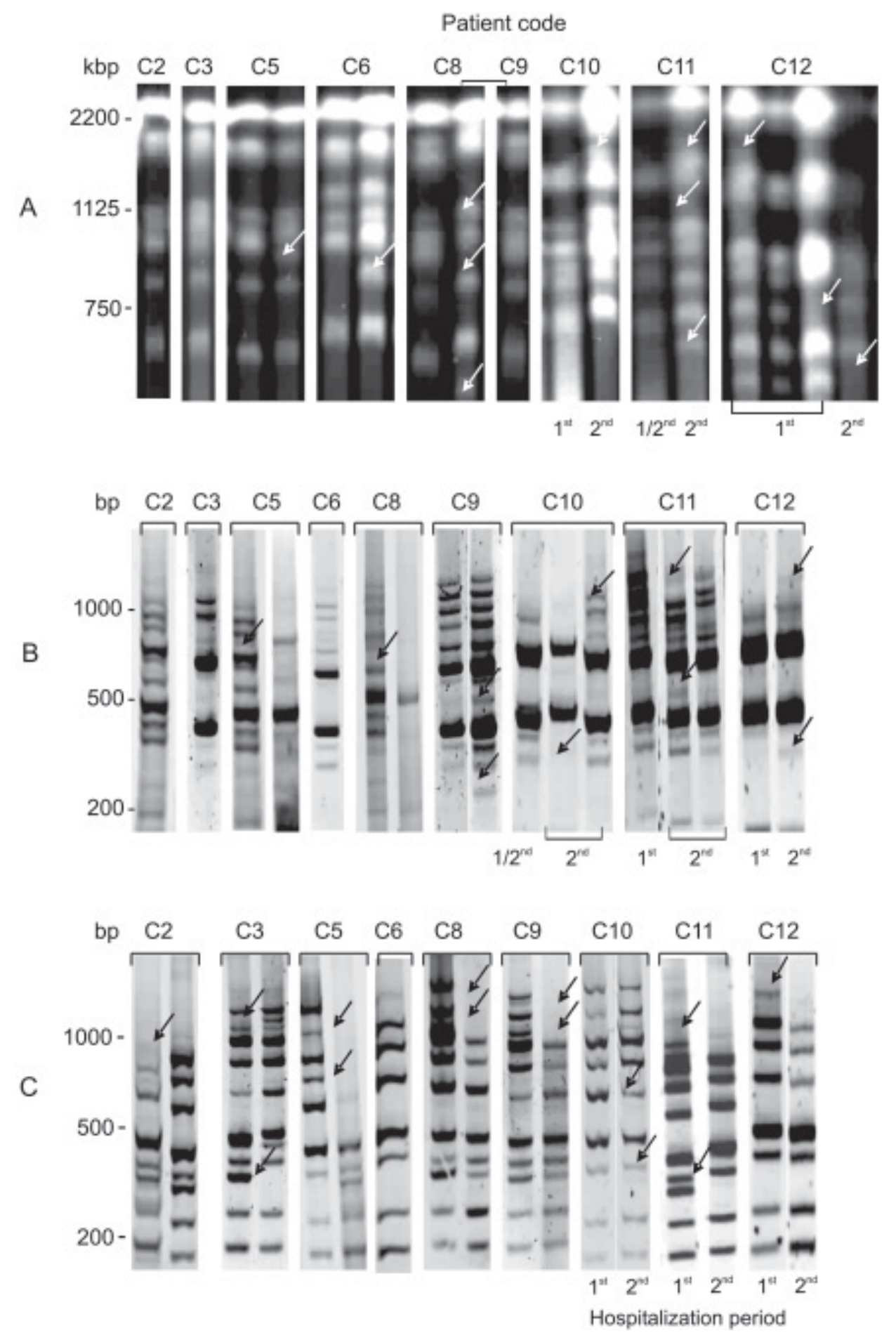

Fig. 1: differences in band profiles of clinical C. neoformans isolates from patients with one cryptococcosis episode and hospitalization (hosp) (group 1 - C2, C3, C5, C6, C8, and C9) and with two episodes and hospitalizations (group 2 - C10, C11, and C12). A: karyotype analyses (pulsed field electrophoresis). Lanes - C2, C3, and C9: all isolates; C5: left lane, isolate $a$, right lane isolate $b$; C6: left lane, isolates $a-e, g$, right lane $f, h)$; C8: left lane, isolates $a-c$, right lane $d$; C10: left lane all isolates of 1st hosp, right lane all isolates, 2nd hosp; C11: left lane, single isolate $a$, 1st hosp, isolate $b$, 2nd hosp; right lane, isolates $c, d$, 2nd hosp; C12: the three first lanes, isolates $a, b$, and, $c-d$, respectively, 1st hosp; fourth lane, single isolate, 2nd hosp. B: RAPD-PCR with primer Pr3. Lanes - C2, C3, and C6: all isolates; C5: left lane, isolate $a$, right lane, $b$; C8: left lane, isolates $a$ - $b$, right lane, $c, d$; C9: left lane, isolates $a-b$; right lane, $c-d$; C10: left lane, all isolates-1st hosp; isolate $f$, 2nd hosp; central lane, isolate $d$ of 2 nd hosp; right lane, isolate $e$, 2nd hosp; C11: left lane, single isolate, 1st hosp; central lane, isolate $b$, 2nd hosp; right lane, isolates $c, d, 2$ nd hosp; C12: left lane, all isolates, 1st hosp; right lane, single isolate, 2nd hosp. C: RAPD-PCR with primer Pr4. Lane - C6: all isolates; C2: left lane, isolates $a-c$; right lane, $d$; C3: left lane-isolates $a-c$, right line, $d$; C5: left lane-isolate $a$; right lane, $b$; C8: left lane-isolates $a-c$, right line, $d$; C9: left lane-isolates $a-b ;$ right line, $c-d$; C10: left lane, all isolates, 1st hosp, right line, all isolate, 2nd hosp; C11: left lane, single isolate, 1st hosp, right line, all isolates, 2nd hosp; C12: left lane, all isolates, 1st hosp, right lane, single isolate, 2nd hosp. The arrows show some differences between the profiles. 
al. 1997, Calvo et al. 2001, Horta et al. 2002, Barreto de Oliveira et al. 2004, Jain et al. 2005, Litvintseva et al. 2006, Almeida et al. 2007). In general, molecular methods were employed to distinguish varieties and serotypes. One of the strategies is to apply PFGE and/or RAPD-PCR in clinical samples (Barchiesi et al. 1995, Haynes et al. 1995, Sullivan et al. 1996, Franzot et al. 1997, Klepser \& Pfaller 1998, Sukroongreung et al. 2001, Almeida et al. 2007).

$C$ neoformans karyotype from clinical isolate profiles were composed of 7-15 bands as those described by others (Wickes et al. 1994, Barchiesi et al. 1995), and concordant with biochemical characterization (all isolates showed the same colony morphology in Niger seed agar). The genetic diversity observed in the majority of the clinical isolates seems to be consistent. The discriminatory capacity to distinguish differences was increased by the combination of both methodologies. PFGE established chromosomal differences, but $C$. neoformans chromosomes had high molecular mass (about 700 to $2200 \mathrm{kbp}$ ). As in PFGE, small alterations in some gene regions could be difficult to observe and this method is time-consuming, we opted for a second methodology. RAPD-PCR is a good method for distinguishing small genetic differences. The employment of two primers doubled the possibility of finding such small differences. These genetic alterations were further confirmed by the similarity coefficient index.

The analysis of isolates from patients belonging to group 1 showed whether genetic diversity may be associated only in recurrent infections. Isolates from patients $\mathrm{C} 1$ (with 2 isolates), C4 (with 7 isolates) and C7 (with 4 isolates) presented the same profile (PFGE, RAPD-PCR $\operatorname{Pr} 3$, and Pr4). These data strongly suggest that these patients were infected with a single $C$. neoformans strain. Despite a single well-separated yeast colony being selected for genotyping, the possibility of arbitrarily selecting the same strain is minimal because several isolates were obtained from each patient. Isolates from patients C2 (4 isolates) and C3 (4 isolates) presented small differences (similarity around $75 \%$ ) detected only in RAPD-PCR with $\mathrm{Pr} 4$ primer. Diversity among isolates was observed in patients C5 (2 isolates), C6 (8 isolates), C8 (4 isolates), and C9 (4 isolates), including chromosomal and genomic alterations. In general, such diversities were observed in the last isolates (Fig. 1). Different infection hypotheses may be formulated based on these results: (a) single isolate (three patients probably were infected with a single isolate and yeasts suffered no mutation), (b) multiple isolates (the other patients could be infected with multiple isolates and were selected in the different collection periods), or (c) mutant isolates (1st isolate could have suffered mutations to adapt and escape from the host immune system and/or the antifungal therapy). These isolates could be selected in the different collection periods, thus some isolates of patients $\mathrm{C} 5, \mathrm{C} 6$, and $\mathrm{C} 8$ may have already presented chromosomal differences.

Diversity was detected with both methodologies, when analyzing isolates collected in the 1st and 2nd hospitalizations of patients belonging to group 2 . These results may suggest that patients $\mathrm{C} 10$ and $\mathrm{C} 11$ probably hosted the initial isolate in both collection times. However, they showed to be infected with other isolates, which could have been obtained in the period between hospitalizations. The genetic diversities observed in isolates from group 1 may be explained by the same hypotheses for group 1: selection during the CSF collection, because infection could have been caused by multiple isolates (multiple isolates), or the initial isolate could have suffered mutation for adaptation (mutant isolates). On the other hand, it is important to emphasize that these patients could have been re-infected with new isolates in the period between two hospitalizations. Patients $\mathrm{C} 10, \mathrm{C} 11$ and $\mathrm{C} 12$ returned to the 2nd hospitalization after 155, 75 and 34 days.

These results may suggest the occurrence of yeast mutation explained by the microevolution of the initial fungal population into new genotypic characteristics in order to preserve the species (Tibayrenc 1996). These fungal mutations may occur in humans or in the environment. Our results are similar to those obtained by other authors analyzing colonies immediately isolated from patients (Sullivan et al. 1996, Jain et al. 2005, Almeida et al. 2007), and in vitro colonies maintained for a long time in laboratory (Franzot et al. 1998, Cavalcante et al. 2007). In addition, it has been recently shown that the genome sequence of $C$. neoformans has a significant quantity of transposon elements (Loftus et al. 2005) that may have participated in the yeast microevolution.

The data could be supported by immunological host factors. C. neoformans infection is common in the general population, but despite the high prevalence, cryptococcosis is rare. Several studies have demonstrated positive skin reactions and serological tests in individuals without history of cryptococcosis, but with history of exposure to the yeast, as in pigeon droppings (Schimpff \& Bennett 1975, Chen et al. 1999, Perfect \& Casadevall 2002). In the city of São Paulo, the samples of pigeon droppings collected in an area of high population density showed a high percentage of $C$. neoformans serotype A (Montenegro \& Paula 2000). The dispersion of $C$. neoformans desiccated encapsulated yeast cells proliferate in accumulated dried pigeon dropping acts as a year-round vector (Ellis \& Pfeiffer 1990, GarciaHermoso et al. 1999). Intact hosts, innate and adaptive immunities overcome the ability of $C$. neoformans to cause damage to the host and instead inflict damage to the yeast, resulting in suppression of infection or clearance (Chen et al. 1999, Perfect \& Casadevall 2002). In cases where the immune system is incapable of overcoming the infection, host damage reaches a threshold of clinically definable disease, as in AIDS patients due to immunosuppression especially in cellular response (Perfect \& Casadevall 2002). The genetic polymorphism of $C$. neoformans isolates, the environmental and immunological factors may partly explain the incidence of different episodes in meningoencephalits in AIDS patients, and contribute to specific strategies of treatment and disease prevention. 


\section{REFERENCES}

Almeida AM, Matsumoto MT, Baeza LC, de Oliveira E, Silva RB, Kleiner AA, Melhem MS, Mendes Giannini MJ, Laboratory Group on Cryptococcosis 2007. Molecular typing and antifungal susceptibility of clinical sequential isolates of Cryptococcus neoformans from São Paulo State, Brazil. FEMS Yeast Res 7: 152-164.

Barchiesi F, Hollis RJ, Messer SA, Scalise G, Rinaldi MG, Pfaller MA 1995. Electrophoretic karyotype and in vitro antifungal susceptibility of Cryptococcus neoformans isolates of Aids patients. Diagn Microbiol Infect Dis 23: 99-103.

Barreto de Oliveira MT, Boekhout T, Theelen B, Hagen F, Baroni FA, Lazera MS, Lengeler KB, Heitman J, Rivera ING, Paula CR 2004. Cryptococcus neoformans shows a remarkable genotypic diversity in Brazil. J Clin Microbiol 42: 1356-1359.

Calvo B, Fischman O, Pignatari A, Del Bianco R, Zaror L 1990. Variedades y serotipos de Cryptococcus neoformans en pacientes con sida y neurocriptococosis en São Paulo, Brasil. Rev Inst Med Trop São Paulo 32: 480-482.

Calvo BM, Colombo AL, Fischman O, Santiago A, Thompson L, Lazera MS, Telles F, Fukushima K, Nishimura K, Tanaka R, Myiajy M, Moretti-Branchini ML 2001. Antifungal susceptibilities, varieties, and electrophoretic karyotypes of clinical isolates of Cryptococcus neoformans from Brazil, Chile, and Venezuela. J Clin Microbiol 39: 2348-2350.

Cavalcante SC, Freitas RS, Vidal MSM, Dantas KC, Levi JE, Martins JEC 2007. Evaluation of phenotypic and genotypic alterations induced by long periods of subculturing of Cryptococcus neoformans strains. Mem Inst Oswaldo Cruz 102: 41-47.

CDC-Center for Disease Control 1999. Guidelines for national human immunodeficiency virus case surveillance, including monitoring for human immunodeficiency virus infection and acquired immunodeficiency syndrome. MMWR 48 (RR-13) p. 1-28; [cited 2006 Dec 12]. Available from: http:// nursingworld.org/AJN/2002/june/Wawatch.htm.

Chen LC, Goldman DL, Doering TL 1999. Antibody response to Cryptococcus infection proteins in rodents and human. Infect Immunol 67: 2218-2224.

Chen SCA, Brownlee AG, Sorrell TC, Ruma P, Ellis DH, Pfeiffer T, Speed BR, Nimmo G 1996. Identification by random amplification of polymorphic DNA of a common molecular type of Cryptococcus neoformans var neoformans in patients with Aids or other immunosupressive conditions. J Infec Dis 173: 754-758.

Currie BP, Freundlich LF, Casadevall A 1994. Restriction fragment lenght polymorphism analysis of isolates from Cryptococcus neoformans enviromental (pigeon excreta) and clinical sources in New York city. J Clin Microbiol 34: 1188-1192.

Dufait R, Velho R, De Vroey C 1987. Rapid identification of the two varieties of by D-proline assimilation. Mycoses 30: 482 .

Ellis DH, Pfeiffer TJ 1990. Ecology, life cycle and infectious propagule of Cryptococcus neoformans. Lancet 336: 923-925.

Franzot SP, Hamdan JS, Currie BP, Casadevall A 1997. Molecular epidemiology of Cryptococcus neoformans in Brazil and the United States: evidence for both local genetic differences and a global clonal population structure. J Clin Microbiol 35: 2243-2251.

Franzot SP, Mukherjee J, Cherniak R, Chen LC, Hamdan JS, Casadevall A 1998. Microevolution of a standard strain of
Cryptococcus neoformans resulting in differences in virulence and other phenotypes. Infect Immun 66: 89-97

Franzot SP, Salkin IF, Casadevall A 1999. Cryptococcus neoformans var. grubii: separate varietals status for serotype A isolates. J Clin Microbiol 37: 838-840.

García-Bermejo MJ, Antón J, Ferrer C, Mesegure I, Abad JL, Colom MF 2001. Chromosome lenght polymorphism in clinical and environmental isolates. Rev Iberoam Micol 18: 174-179.

Garcia-Hermoso MJ, Janbon D, Dromer F 1999. Epidemiological evidence for dormant Cryptococcus neoformans infection. J Clin Microbiol 37: 3204-3209.

Haynes KA, Sullivan DJ, Coleman DC, Clarke JC, Emilianus R, Atkinson C, Cann KJ 1995. Involvement of multiple Cryptococcus neoformans strains in a single episode of Cryptococcosis and reinfection with novel strains in recurrent infection demonstrated by random amplification of polymorphic DNA and DNA fingerprinting. J Clin Microbiol 33: 99-102.

Horta JA, Staats CC, Casali AK, Ribeiro AM, Schrank IS, Scharank A, Vainstein MH 2002. Epidemiological aspects of clinical and environmental Cryptococcus neoformans isolates in the Brazilian state Rio Grande do Sul. Med Mycol 40: 565-571.

Igreja RP, Lazera MS, Wanke B, Galhardo MCG, Kidd SE, Meyer W 2004. Molecular epidemiology of Cryptococcus neoformans isolates from AIDS patients of the Brazilian city, Rio de Janeiro. Med Mycol 42: 229-238.

Ikeda R, Nishikawa A, Shinoda T, Fukazawa Y 1985. Chemical characterization of capsular polysaccharide from Cryptococcus neoformans serotype A-D. Microbiol Immunol 29: 981-991.

Jain N, Wickes BL, Keller SM, Fu J, Casadevall A, Jain P, Ragan MA, Banerjee U, Fries BC 2005. Molecular Epidemiology of Clinical Cryptococcus neoformans Strains from India. $J$ Clin Microbiol 43: 5733-5742.

Klepser ME, Pfaller MA 1998. Variation in electrophoretic karyotipe and antifungal susceptibility of clinical isolates of Cryptococcus neoformans at a university-affiliated teaching hospital from 1987 to 1994. J Clin Microbiol 36: 3653-3656.

Kwon-Chung KJ 1998. Cryptococcus. In CP Kurtzman, JW Fell, The yeasts: a taxonomic study, Elsevier, Amsterdam, p. 656662.

Kwon-Chung KJ, Bennett JE 1992. Cryptococcosis. In KJ KwonChung, JE Bennett, Medical Mycology, Lea \& Febiger, Philadelphia, p. 397-446.

Kwon-Chung KJ, Varma SA 2006. Do major species concepts support one, two or more species within Cryptococcus neoformans? FEMS Yeast Res 6: 574-587.

Litvintseva AP, Thakur R, Vilgalys R, Mitchell TG 2006. Multilocus sequence typing reveals three genetic subpopulations of Cryptococcus neoformans var. grubii (serotype A), including a unique population in Botswana. Genetics 172: 2223-2238.

Loftus BJ, Fung E, Roncaglia P, Rowley D, Amedeo P, Bruno D, Vamathevan J, Miranda M, Anderson IJ, Fraser JA, Allen JE, Bosdet IE, Brent MR, Chiu R, Doering TL, Donlin MJ, D'Souza CA, Fox DS, Grinberg V, Fu J, Fukushima M, Haas BJ, Huang JC, Janbon G, Jones SJ, Koo HL, Krzywinski MI, Kwon-Chung JK, Lengeler KB, Maiti R, Marra MA, Marra RE, Mathewson CA, Mitchell TG, Pertea M, Riggs FR, Salzberg SL, Schein JE, Shvartsbeyn A, Shin H, Shumway 
M, Specht CA, Suh BB, Tenney A, Utterback TR, Wickes BL, Wortman JR, Wye NH, Kronstad JW, Lodge JK, Heitman J, Davis RW, Fraser CM, Hyman RW 2005. The genome of the basidiomycetous yeast and human pathogen Cryptococcus neoformans. Sience 307: 1321-1324.

Meyer W, Marszewska K, Amirmostofian M, Igreja RP, Hardtke C, Methling K, Viviani MA, Chindamporn A, Sukroongreung S, John MA, Ellis DH, Sorrell TC 1999. Molecular typing of global isolates of Cryptococcus neoformans var. neoformans by polymerase chain reaction fingerprinting and randomly amplified polymorphic DNA - a pilot study to standardize techniques on which to base a detailed epidemiological survey. Electrophoresis 20: 1790-1799.

Mitchell TG, Perfect PT 1995. Cryptococcosis in the era of AIDS 100 years after the discovery of Cryptococcus neoformans. Clin Microbiol Rev 8: 515-548.

Montenegro H, Paula CR 2000. Environmental isolation of Cryptococcus neoformans var. gattii and C. neoformans var. neoformans in the city of São Paulo, Brazil. Med Mycol 38: 385-390.

Nishikawa MM, Lazera MS, Barbosa GG, Trilles L, Balassiano BR, Macedo RCL, Bezerra CCF, Perez MA, Cardarelli P, Wanke B 2003. Serotyping of 467 Cryptococcus neoformans isolates from clinical and environmental sources in Brazil: analysis of host and regional patterns. J Clin Microbiol 41: 73-77.

Oliveira JF, Greco DB, Oliveira GC, Christo PP, Guimarães MD, Oliveira RC 2006. Neurological disease in HIV-infected patients in the era of highly active antiretroviral treatment: a Brazilian experience. Rev Soc Bras Med Trop 39: 146-151.

Pappalardo MC, Melhem MS 2003. Cryptococcosis: a review of the Brazilian experience for the disease. Rev Inst Med Trop São Paulo 45: 299-305.

Perfect JR, Magee BB, Magee PT 1989. Separation of chromosomes of Cryptococcus neoformans by pulsed field gel electrophoresis. Infect Immun 57: 2624-2627.

Perfect JR, Casadevall A 2002. Cryptococcosis. Infect Dis Clin North Am 16: 837-874.

Pfaller MA, Messer SA, Boyken L, Rice C, Tendolkar S, Hollis RJ, Doern GV, Diekema DJ 2005. Global trends in the antifungal susceptibility of Cryptococcus neoformans (1990 to 2004). J Clin Microbiol 43: 2163-2167.
Sacktor N 2002. The epidemiology of human immunodeficiency virus-associated neurological disease in the era of highly antiretroviral therapy. J Neurovirol 8: 115-121.

Sambrook J, Fritsch EF, Maniatis T 1989. Commonly used techniques in molecular cloning. In J Sambrook, EF Fritsch, T Maniatis, Molecular cloning. A laboratory manual, appendix E, Cold Spring Harbour Laboratory Press, New York, p. 3-6.

Santos NJS, Tayra A, Silva SR, Buchalla CM, Laurenti R 2002. AIDS in the State of São Paulo. Changes in the profile of the epidemic and prospects for epidemiological surveillance. Rev Bras Epidemiol 5: 286-310.

Saag MS, Powderly WG, Cloud GA, Robinson P, Grieco MH, Sharkey PK, Thompson SE, Sugar AM, Tuazon CU, Fisher JF, Hyslop N, Jacobson JM, Hafner R, Dismukes WE 1992. Comparison of amphotericin $\mathrm{B}$ with fluconazole in the treatment of acute AIDS-associated cryptococcal meningitis. The NIAID Mycoses Study Group and the AIDS Clinical Trials Group. New Engl J Med 326: 83-89.

Schimpff SC, Bennett JE 1975. Abnormalities in cell-mediated immunity in patients with Cryptococcus neoformans infection. J Allergy Clin Immunol 55: 430-441.

Silva MT, Araujo A 2005. Highly active antiretroviral therapy access and neurological complications of human immunodeficiency virus infection: Impact versus resources in Brazil. $J$ Neurovirol 11: 11-15.

Soll DR 2000. The ins and outs of DNA fingerprinting the infectious fungi. Clin Microbiol Rev 13: 332-370.

Sukroongreung S, Lim S, Tantimavanich S, Eampokalap B, Carter D, Nilakui C, Kulderatiyut S, Tanshyphaswadikui S 2001. Phenotypic switching and genetic diversity of Cryptococcus neoformans. J Clin Microbiol 39: 2060-2064.

Sullivan D, Haynes K, Moran G, Shanley D, Coleman D 1996. Persistence, replacement and microevolution of Cryptococcus neoformans strains in recurrent meningitis in AIDS Patients. J Clin Microbiol 34: 1739-1744.

Tibayrec M 1996. Towards a unified evolutionary genetics of microorganisms. Ann Rev Microbiol 50: 401-429.

Wickes BL, Moore TDE, Kwon-Chung KJ 1994. Comparison of the electrophoretic karyotypes and chromosomal location of ten genes in the two varieties of Cryptococcus neoformans. Microbiol 140: 543-550. 